\title{
KẾT QUẢ ĐIỀU TR! PHÌNH ĐộnG MẠCH CHỦ BẰnG CAN THIỆP NỘI MẠCH TẠI KHOA LỒNG NGỰC MẠCH MÁU - BỆNH VIỆN ĐẠI HỌC Y DỰ̛̣C TPHCM
}

\author{
Trần Thanh Vĩ ${ }^{*}$, Lê Phi Long ${ }^{*}$, Lê Quang Đình ${ }^{*}$, Lê Thanh Phong, ${ }_{*}^{*}$
} Trần Minh Bảo Luân ${ }^{*}$, Lê Thị Ngoc Hằng ${ }^{*}$, Đào Duy Phuơng*, Luơng Việt Thắng*, Hồ Tất Bằng*

\section{TÓM TÁT}

32 trường hợp phình động mạch chủ được can thiệp ( 25 nam và 7 nữ), tuổi trung bình là 73 tuổi, gồm 24 ca phình động mạch chủ bụng và 8 ca phình động mạch chủ ngực trong đó có 2 ca phình kèm bóc tách động mạch chủ ngực tuýp B, 4 ca được phẫu thuật debranching trước khi làm stent graft. 5 trường hợp dùng ống ghép của ELLA và 27 trường hợp dụng ống ghép của Medtronic, tất cả đều đặt thành công. Có $02 \mathrm{ca}$ tử vong, 1 ca ngày thứ 10 sau can thiệp vì chảy máu sau phúc mạc mặc dù đã phẫu thuật mở bụng cấp cứu, 1 ca tử vong vì nhồi máu cơ tim cấp. Thời gian nằm viện trung bình là $8,1 \pm 2,3$ ngày, thời gian nằm hồi sức hậu phẫu trung bình là $2,1 \pm 1,0$ ngày. Can thiệp nội mạch đặt stent graft điều trị phình động mạch chủ là phương pháp nhẹ nhàng, xâm lấn tối thiểu. Tuy nhiên cần đánh giá kỹ tổng trạng của bệnh nhân và đặc điểm giải phẫu của túi phình để đưa ra chỉ định và hướng xử trí phù hợp để hạn chế tử vong và biến chứng.

Tù khóa: Phình động mạch chủ, Stent graft.

\section{ABSTRACT}

THE RESULTS OF ENDOVASCULAR ANEURYSMS REPAIR AT THORACIC VASCULAR DEPARTMENT, UNIVERSITY MEDICAL CENTER HCMC

32 patients, 25 men and 7 women, means age is 73 . There are 24 case of abdominal aortic aneurysm and 8 cases of thoracic aortic aneursyms which treat by endovascular repair with stent graft. 4 cases spent debranching before endovascular repair. 1 patient died from endoleak
10 day after intervention although spent emergency open surgery repair and 1 patients die from myocardial infarction. Mean length of hospital stay after intervention was $8.1 \pm 2.3$ days Endovascular repairs with stent graft for aortic aneurysms is a minimum invasive procedure. Better to evaluate patients condition, aneurysms's anatomy to decide suitable interventional indication and method to reduce mortality and complication rate.

Keywords: Aortic aneurysm, stent graft.

\section{I. ĐặT VẤN ĐỀ}

Thuật ngữ phình động mạch mô tả sự giãn nở bất thường của mạch máu. Phình động mạch xảy ra trên toàn cơ thể nhưng phổ biến nhất là phình động mạch chủ bụng. Ở Anh, phình động mạch chủ đã gây ra khoảng 13.000 người chết trong 1997. Nói chung, tỷ lệ mắc chứng phình động mạch tăng cùng với tuổi tác, nhưng bệnh phình động mạch cũng có thể xảy ra ở bất kỳ độ tuổi nào do kết quả của thoái hóa, bao gồm cả trong điều kiện tự nhiên, nhiễm trùng, di truyền và chấn thương. ${ }^{[1]}$ Bệnh gây ra hậu quả nghiêm trọng với khoảng $50 \%$ các trường hợp tử vong do vỡ khối phình nếu không được điều trị.

Tỷ lệ vỡ khối phình động mạch chủ bụng hàng năm tăng theo kích thước khối phình: $<1 \%(3-4 \mathrm{~cm}), 3-5 \%$ (4-5cm), 5-7\% (5-6cm), $7-$ $19 \%(6-7 \mathrm{~cm})$ và $>20 \%$ nếu kích thước khối phình $>7 \mathrm{~cm}^{[2]}$

* Khoa Lồng ngực Mạch máu, Bệnh viện Đại học Y Dược TP. Hồ Chi Minh

Người chịu trách nhiệm khoa học: ThS. BS. Trần Thanh Vỹ

Ngày nhận bài: 01/05/2018 - Ngày Cho Phép Đăng: 20/05/2018

Phản Biện Khoa học: PGS.TS. Đặng Ngoc Hùng GS.TS. Lê Ngoc Thành 
Hiện nay, mổ mở thay đoạn phình ĐMC vẫn là phương pháp điều trị triệt để nhưng khá nặng nề với đa số trường hợp phình ĐMC là những trường họp lớn tuổi, nhiều bệnh nội khoa đi kèm. Bên cạnh đó, phình động mạch chủ bụng trên thận hoặc đoạn ngực đặt ra nhiều vấn đề như phải cắm lại các mạch máu tạng, tủy sống và nhất là những hậu quả do kẹp động mạch chủ trên thân tạng. Can thiệp nội mạch điều trị phình ĐMC lần đầu tiên được giới thiệu bởi tác giả Parodi vào năm $1991^{[3]}$ và ngày càng phát triển. Nhiều nghiên cứu cho thấy can thiệp nội mạch có kết quả 30 ngày tốt hơn và kết quả lâu dài tương đương với mổ mở kinh điển ${ }^{[5]}$.

Tại Việt Nam, một số trung tâm đã triển khai can thiệp như bệnh viện (BV) Việt Đức, BV Bạch Mai, BV Đại học Y Hà Nội, BV Chợ Rẫy, BV Bình Dân ${ }^{[6]}$, tuy nhiên, số lượng các trường hợp còn hạn chế và chưa có những nghiên cứu lâm sàng cụ thể. Tại bệnh viện Đại học y dược TP Hồ Chí Minh, chúng tôi đã tiến hành can thiệp đặt ống ghép nội mạch điều trị bệnh lý động mạch chủ từ tháng 1 năm 2014. Đề tài này được thực hiện với mục đích đánh giá lại chỉ định và chiến lược can thiệp nội mạch điều trị phình động mạch chủ ngực và chủ bụng qua những trường hợp đã thực hiện tại Bệnh viện Đại học Y Dược TPHCM.

\section{II. ĐỐI TƯợNG VÀ PHƯƠNG PHÁP NGHIÊN CÚU}

Loại hình nghiên cúu: Báo cáo hàng loạt ca.

Đối tựng nghiên cứu: Tất cả các trường hợp được can thiệp nội mạch điều trị phình động mạch chủ ngực và chủ bụng tại Khoa Lồng ngực Mạch máu BV Đại học Y Dược TP Hồ Chí Minh từ tháng $1 / 2014$ đến tháng $7 / 2017$.

* Đối với túi phình động mạch chủ bụng (ĐMCB):

Khi được chẩn đoán xác định phình ĐMCB, bệnh nhân được can thiệp nội mạch nếu có chỉ định: (1) phình ĐMC không triệu chứng đường kính >45mm; (2) phình ĐMC không triệu chứng đường kính $>2$ lần đường kính bình thường; (3) phình ĐMC không triệu chứng đường kính tăng $>5 \mathrm{~mm}$ trong 6 tháng; (4) phình ĐMC hình túi; (5) phình ĐMC có triệu chứng; (6) phình ĐMC võ̃, huyết động ổn định. (7) Phình động mạch chủ kèm bóc tách.

Khối phình có giải phẫu thích hợp: (1) cổ túi phình có chiều dài $>15 \mathrm{~mm}$, không vôi hoá, huyết khối nhiều, góc gập $<75^{\circ}$; (2) đường kính ĐM chậu 7-22mm; (3) đường kính ĐMCB bình thường 14-32mm.

Các chống chỉ định tuyệt đối: (1) đặc điểm giải phẫu không thích hợp: cổ túi phình có chiều dài<10mm, góc gập $>90^{\circ}$, tắc 2 ĐM chậu; (2) dị ứng chất cản quang; (3) bệnh nhân toàn trạng già yếu, nhiều bệnh nội khoa trầm trọng phối hợp, có nguy cơ cao biến chứng và tử vong.

Các chống chỉ định tương đối: (1) đặc điểm giải phẫu không phù hợp: cổ túi phình có chiều dài $10-15 \mathrm{~mm}$, góc gập $75-90^{\circ}$, cổ túi phình hình nón, huyết khối hoặc vôi hoá nhiều, ĐM chậu đùi 1 hay 2 bên hẹp, quá ngoằn ngoèo, đã được phẫu thuật; (2) tiên lượng sống chung < 1 năm; (3) suy thận.

\section{* Đối với túi phình động mạch chủ ngục:}

Bệnh nhân thường không có triệu chứng, hoặc đau ngực không đặc hiệu, triệu chứng chèn ép các cơ quan xung quanh như ho, khàn tiếng, khó thở, nuốt khó. Khi nghi ngờ chúng tôi chỉ định chụp CTscan ngực có cản quan. Bệnh nhân được chỉ định can thiệp nội mạch nếu có chỉ định: (1) Túi phình không triệu chứng có đường kính lớn nhất $>5,5 \mathrm{~mm}$, (2) túi phình có đường kính tăng nhanh $>5 \mathrm{~mm}$ trong vòng 6 tháng, (3) phình dạng túi, (4) Phình động mạch chủ ngực có triệu chứng, (5) phình dọa vỡ hoặc vỡ, (6) Phình kèm bóc tách động mạch chủ. 


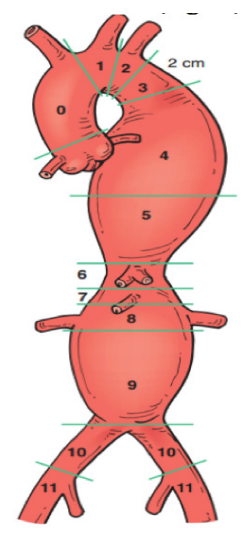

Hình 1. 11 vùng giải phẫu của động mạch chủ

Chúng tôi sử dụng phần mềm OsiriX để phân tích kết quả CT scan, đánh giá cấu trúc giải phẫu của túi phình và các nhánh động mạch liên quan. Quá trình can thiệp được thực hiện ở phòng DSA, vô cảm bằng mê nội khí quản, sử dụng heparin tĩnh mạch 50 đơn vị/kg ngay trước phẫu thuật. Bộc lộ $\mathrm{ĐM}$ đùi chung 2 bên để tạo đường đưa ống ghép vào lòng $\mathrm{DMC}$ và ĐM chậu. Thân chính của ống ghép có đường kính lớn hơn cổ túi phình từ 10-20\% được bung ra sau khi chụp cản quang xác định vị trí các mốc giải phẫu quan trọng, việc luồn dây dẫn vào chân ngắn của thân chính ống ghép sẽ được kiểm tra chắc chắn bằng cách xoay ống dẫn pigtail ở trong thân chính ống ghép, các ống ghép nối tiếp từ thân chính đến các ĐM chậu được bung sau khi chụp xác định vị trí ĐM chậu trong. Chụp kiểm tra lần cuối.

Các trường hợp phình động mạch chủ ngực ở vùng $0,1,2,3$ (Hình 2) tùy vị trí của túi phình mà bệnh nhân được phẫu thuật Debranching chuyển vị các nhánh động mạch quan trọng trước khi thực hiện kỹ thuật đặt stent graft.
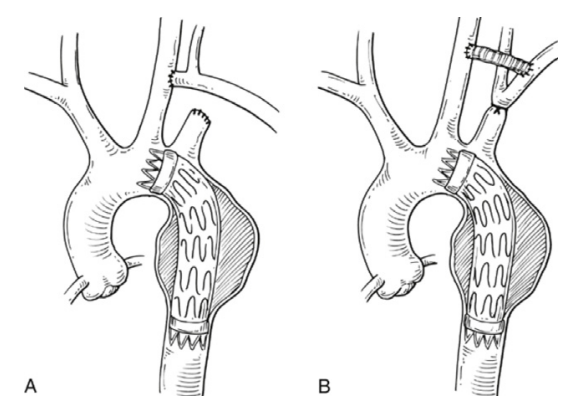

Hinh 2. Chuyển vị (Debranching) động mạch

\section{KẾT QUẢ NGHIÊN CÚU}

Từ tháng 1 năm 2014 đến tháng 7 năm 2017 có 32 trường hợp phình động mạch chủ được can thiệp ( 25 nam và 7 nữ), tuổi trung bình là 73 tuổi, nhỏ nhất là 53 tuổi và lớn nhất là 83 tuổi.

Trong 32 bệnh nhân được can thiệp, chỉ có 17 bệnh nhân $(53,1 \%)$ có triệu chứng, 2 trong số 8 bệnh nhân phình động mạch chủ ngực có triệu chứng đau ngực mơ hồ, trong 24 bệnh nhân phình động mạch chủ bụng, có 15 bệnh nhân đau bụng âm ỉ, sờ bụng thấy khối đập theo nhịp tim. Không có bệnh nhân nào vào viện vì tắc mạch ngoại biên.

Bảng 3.1. Đặc điểm bệnh nhân được can thiệp $(\mathrm{N}=32)$

\begin{tabular}{|l|c|}
\hline Đặc điểm & Giá trị \\
\hline Tuổi trung bình & 73 \\
\hline Hút thuốc lá & $16(51,6 \%)$ \\
\hline Tăng huyết áp & $20(64,5 \%)$ \\
\hline Suy tim & $2(6,4 \%)$ \\
\hline Bệnh mạch vành & $9(29,3 \%)$ \\
\hline Rối loạn lipid máu & $21(67,7 \%)$ \\
\hline Đái tháo đường & $7(22,5 \%)$ \\
\hline Bệnh động mạch ngoại biên & $7(22,5 \%)$ \\
\hline Suy thận mạn & $2(6,4 \%)$ \\
\hline Bệnh phổi tắc nghẽn mạn tính & $4(12,9 \%)$ \\
\hline
\end{tabular}

Bảng 3.2. Đặc điểm của can thiệp $(\mathrm{N}=32)$

\begin{tabular}{|l|c|c|}
\hline \multicolumn{1}{|c|}{ Đặc điểm } & $\begin{array}{c}\text { Số truò̀ng } \\
\text { hợp }\end{array}$ & $\begin{array}{c}\text { Tỉ lệ (\%) } \\
\text { Trung bình }\end{array}$ \\
\hline Chương trình & 17 & $53 \%$ \\
\hline Cấp cứu, bán cấp & 15 & $47 \%$ \\
\hline Thời gian can thiệp & & $\begin{array}{c}120 \text { phút } \pm 70 \\
\text { phút }\end{array}$ \\
\hline Thời gian nằm viện & & $8,1 \pm 2,3$ ngày \\
\hline
\end{tabular}




\begin{tabular}{|l|c|c|}
\hline Cách thức vô cảm & & \\
\hline $\begin{array}{l}\text { - Tê tại chỗ } \\
\text { - Gây mê toàn thân }\end{array}$ & 28 & $\begin{array}{l}12,5 \% \\
87,5 \%\end{array}$ \\
\hline $\begin{array}{l}\text { Phình động mạch } \\
\text { chủ bụng }\end{array}$ & 24 & $75 \%$ \\
\hline $\begin{array}{l}\text { Phình động mạch } \\
\text { chủ ngực }\end{array}$ & 08 & $25 \%$ \\
\hline $\begin{array}{l}\text { Chuyền vị trước } \\
\text { can thiệp }\end{array}$ & 04 & $12,5 \%$ \\
\hline
\end{tabular}

Bảng 3.3. Tai biến, biến chứng sau mổ

\begin{tabular}{|l|c|c|}
\hline \multicolumn{1}{|c|}{ Biến chúng } & $\begin{array}{c}\text { Số trùòng } \\
\text { họp }\end{array}$ & $\begin{array}{c}\text { Ti lệ } \\
\text { (\%) }\end{array}$ \\
\hline Nhồi máu cơ tim & 1 & 3,1 \\
\hline Chảy máu sau can thiệp & 1 & 3,1 \\
\hline Viêm phổi & 2 & 6,2 \\
\hline Tử vong & 2 & 6.2 \\
\hline
\end{tabular}

Trong các ca can thiệp, có 8 ca (25\%) bệnh mạch vành cần can thiệp đặt stent trước khi can thiệp phình động mạch chủ, 1 ca phẫu thuật máu tụ ngoài màng cứng bán cầu não trước lúc can thiệp 15 ngày.

Về mặt giải phẫu học của phình ĐMC, có 24 ca phình động mạch chủ bụng và 8 ca phình động mạch chủ ngực trong đó có 2 ca phình kèm bóc tách động mạch chủ ngực tuýp $\mathrm{B}, 4$ ca phình ĐMC ngực được phẫu thuật Debranching trước khi làm stent graft, 4 ca phình động mạch chủ ngực đoạn xuống. Trong 24 ca phình ĐMC bụng, có 8 trường hợp phình động mạch chủ kèm phình động mạch chậu chung trái, 8 ca phình động mạch chủ đơn thuần, 6 trường hợp phình động mạch chủ bụng kèm phình động mạch chậu chung phải, 2 trường hợp phình ĐMCB kèm phình 2 động mạch chậu chung.

Bảng 3.4. Đặc điểm những ca phình động mạch chủ bụng

\begin{tabular}{|l|c|c|c|}
\hline \multicolumn{1}{|c|}{ Đặc điểm } & Trung bình & Lón nhất & Nhỏ nhất \\
\hline Chiều dài cổ túi phình (mm) & $35,0 \pm 14,4$ & 80 & 15 \\
\hline Đường kính cổ túi phình (mm) & $20,5 \pm 2,6$ & 26 & 15 \\
\hline Góc cổ túi phình (độ) & $49,6 \pm 21,3$ & 90 & 14 \\
\hline Đường kính túi phình (mm) & $55,1 \pm 14,5$ & 77 & 21 \\
\hline Chiều dài túi phình (mm) & $88,1 \pm 29,1$ & 133 & 42 \\
\hline Đường kính ngã 3 chủ chậu (mm) & $32,4 \pm 12,2$ & 64 & 17 \\
\hline
\end{tabular}

\section{BÀN LUẬN}

Hầu hết những bệnh nhân phình động mạch chủ đều lớn tuổi, độ tuổi trung bình 73 tuổi, tỷ lệ rối loạn lipid máu cao $(67,7 \%)$, tỷ lệ có bệnh lý tim mạch khá cao $(64,5 \%$ tăng huyết áp, 29,3\% bệnh mạch vành, $6,4 \%$ suy tim), trong đó 8 trường hợp $(25 \%)$ cần can thiệp mạch vành trước khi can thiệp ĐMC. Theo các nghiên cứu, trong các bệnh nhân phình động mạch chủ bụng có nguy cơ phẫu thuật cao được điều trị mổ hở hoặc can thiệp nội mạch, tỷ lệ các bệnh lý tim phối hợp từ $41 \%-46 \%{ }^{[4]}$. Đây là bệnh lý chủ yếu làm tăng tỷ lệ tử vong trong và sau mổ. Trong những bệnh nhân đầu tiên can thiệp có một bệnh nhân tử vong do nhồi máu cơ tim trong thời gian nằm hậu phẫu ngày thứ 3 , nguyên nhân là do bệnh nhân có bệnh mạch vành nhưng tầm soát chưa tốt. Do đó, những bệnh nhân tiếp theo, để giảm thiểu các biến chứng trong và sau mổ, chúng tôi đã đề ra quy trình tầm soát các bệnh lý kèm theo ở mọi trường hợp phình ĐMC, đặc biệt lưu ý việc tầm soát kỹ những bệnh lý tim mạch. Bệnh nhân được chụp mạch vành chẩn đoán nếu có 1 trong các tiêu chuẩn sau: (1) tiền căn bệnh lý mạch vành đã 
được chẩn đoán như nhồi máu cơ tim, thiếu máu cơ tim, đã được can thiệp hay phẫu thuật mạch vành; (2) tiền sử đau thắt ngực điển hình; (3) điện tâm đồ có dấu hiệu thiếu máu hay nhồi máu cơ tim; (4) siêu âm tim có rối loạn vận động vùng và (5) trên hình ảnh CT-scan thấy vôi hoá mạch vành. Nếu có chỉ định, bệnh nhân sẽ được can thiệp hay phẫu thuật mạch vành trước can thiệp đặt ống ghép nội mạch điều trị phình ĐMC.

Trong 32 bệnh nhân có 15 bệnh nhân không có triệu chứng phình động mạch chủ, chỉ phát hiện tình cờ, điều này cho thấy rằng, phình động mạch chủ thường diễn tiến âm thầm, và chỉ biểu hiện khi có dấu hiệu dọa vỡ hoặc vỡ phình. Do đó, chúng tôi đề xuất tầm soát bệnh lý động mạch chủ nhất là động mạch chủ bụng ở những bệnh nhân lớn tuổi.

Trong 2 ca tử vong sau can thiệp, có 1 ca tử vong do chảy máu sau phúc mạc, bệnh nhân sau đặt ngày thứ 7 có biểu hiện tê chân phải, công thức máu thiếu máu nặng. Bệnh nhân được chụp CT scan phát hiện khối máu tụ lớn sau phúc mạc, được chỉ định mở bụng cấp cứu, bệnh nhân tử vong 3 ngày sau đó do viêm phổi nặng, suy đa cơ quan. Biến chứng này cho endoleak gây vỡ túi phình ĐM chậu phải, và tụ máu sau phúc mạc nhưng không được phát hiện kịp thời. Do đó, những bệnh nhân sau đó, chúng tôi theo dõi sát diễn tiến hậu phẫu, nhất là các triệu chứng về cấp máu 2 chi dưới, công thức máu 2 ngày 1 lần trong vòng 7 ngày đầu.

\section{KẾT LUẬN}

Bệnh lý phình động mạch chủ là bệnh lý gặp chủ yếu ở người lớn tuổi, thường kèm theo bệnh lý nội khoa nặng nề, nhiều yếu tố nguy cơ, thường không có triệu chứng lâm sàng hoặc là triệu chứng mơ hồ không đặc hiệu. Việc tầm soát phát hiện bệnh lý động mạch chủ bụng nên thực hiện thường quy ở những bệnh nhân lớn tuổi, có nhiều yếu tố nguy cơ như hút thuốc lá, bệnh mạch vành, rối loạn mỡ máu.
Điều trị chủ yếu hiện nay, ngoài can thiệp phẫu thuật mở truyền thống thì can thiệp nội mạch đặt stent graft là phương pháp can thiệp mới, ít xâm lấn, thời gian nằm hồi sức và nằm viện ngắn nhưng cũng tiềm ẩn nguy cơ tử vong và biến chứng khá cao nếu không được tầm soát và kiểm soát tốt các bệnh lý nội khoa kèm theo đặc biệt là bệnh lý tim mạch. Sau can thiệp, bệnh nhân cần được theo dõi sát triệu chứng lâm sàng để phát hiện kịp thời các biến chứng để xử trí kịp thời.

\section{TÀI LIỆU THAM KHẢO}

1. Jack L. Cronenwett, Wayne K. Johnston (2014), Rutherford's Vascular Surgery, ed. 8th. Vol. 1

2. Alfío Carroccio và Larry H. Hollier (2004), Abdominal Aortic Aneurysm. Haimovici's Vascular Surgery . . Vol. 5th edition. Blackwell Publishing 2004. .

3. Parodi JC, Palmaz JC, và Barone HD (1991), Transfemoral intraluminal graft implantation for abdominal aortic aneurysms. Ann Vasc Surg 1991; tr. 5:491-9.

4. De Bruin JL, Baas AF, Buth J, Prinssen et al, và DREAM Study Group (2010), Longterm outcome of open or endovascular repair of abdominal aortic aneurysm., N Engl J Med, tr. 362: 1881-1889.

5. De Bruin JL, Baas AF, Buth J, Prinssen et al, và DREAM Study Group. (2010), Longterm outcome of open or endovascular repair of abdominal aortic aneurysm, N Engl J Med, tr. 362: 1881-1889.

6. Văn Tần, Cardon J.M, và DeSoutter p. (2006), Kết quả ban đầu điều trị phình động mach chủ bung duới thận qua can thiệp nội mạch đặt ống ghép nhân tạo, Tạp Chí Y Học Việt Nam, tr. 328: 160-168.

7. Văn Tần và Trần Công Quyền (2008), Đặc điểm dịch tễ bệnh phinh động mạch chủ bung duới động mach thận ở người Việt Nam, Tạp chí Y học thành phố Hồ Chí Minh, số Tập 12, tr. 215-221. 